Research, part of a Special Feature on Adaptation in Fire-Prone Landscapes: Interactions of Policies, Management. Wildfire, and Social Networks in Oregon, USA

\title{
Integrating Ecological and Social Knowledge: Learning from CHANS Research
}

\author{
Bruce Shindler $^{1}$, Thomas A. Spies ${ }^{2}$, John P. Bolte ${ }^{3}$ and Jeffrey D. Kline ${ }^{4}$
}

\begin{abstract}
Scientists are increasingly called upon to integrate across ecological and social disciplines to tackle complex coupled human and natural system (CHANS) problems. Integration of these disciplines is challenging and many scientists do not have experience with large integrated research projects. However, much can be learned about the complicated process of integration from such efforts. We document some of these lessons from a National Science Foundation-funded CHANS project (Forests, People, Fire) and present considerations for developing and engaging in coupled human and natural system projects. Certainly we are not the first to undertake this endeavor, and many of our findings complement those of other research teams. We focus here on the process of coming together, learning to work as an integrated science team, and describe the challenges and opportunities of engaging stakeholders (agency personnel and citizen communities of interests) in our efforts. Throughout this project our intention was to foster dialogue among diverse interests and, thus, incorporate this knowledge into uncovering primary social and ecological drivers of change. A primary tool was an agentbased model, Envision, that used this information in landscape simulation, visualization models, and scenario development. Although integration can be an end in itself, the proof of value in the approach can be the degree to which it provides new insights or tools to CHANS, including closer interaction among multiple stakeholders, that could not have been reached without it.
\end{abstract}

Key Words: agent-based models; CHANS; coupled human and natural systems; integrating ecological-social knowledge; interdisciplinary teams; lessons learned

\section{INTRODUCTION}

Fire and landscape research has been a top tier concern for scientists now for well over a decade. More recently, this field of study has been included within the coupled human and natural systems (CHANS) approach, which acknowledges and attempts to integrate perspectives, most notably from the ecological and social sciences (Liu et al. 2007, Laurent et al. 2015). As CHANS research evolves, interdisciplinary teams have been brought together to learn from one another and conduct studies in regions where the effects of climate change on fire behavior and ecosystem services can be observed, often using sophisticated computer models. This Special Feature in Ecology and Society encompasses specific research findings from our team of ecologists, social scientists, and agent-based modelers who were engaged in a National Science Foundation CHANS project in central Oregon. We selected this fire-prone region for its history of frequent and sometimes large fires, diversity of vegetation, and subsequent ownership approaches to the risk of fire, vulnerability to climate change, and the presence of several large stakeholder groups, most notably, federally funded Collaborative Forest Landscape Restoration Programs (CFLRP). Our research proposal was titled "Coupled Natural and Human Systems in Fire-Prone Landscapes: Interactions, Dynamics, and Adaptation," which we eventually termed the Forest, People, Fire (FPF) project.

Our objectives were the following: (1) to understand the complexity of social and ecological systems of fire-prone forest landscapes of central Oregon, (2) to use collaborative learning (scientists, management personnel, and key stakeholders) and agent-based models to understand how alternative approaches to forest management and fire risk affect ecological and social outcomes. Our agent-based model, Envision (Spies et al. 2014), incorporates existing ecological models of vegetation and fire and is based on empirical studies of landowner decision making. Our intention was to use this integrated system to explore alternative management strategies and various fire scenarios. A frequent component of CHANS studies, scenario analysis has been described as an approach that transcends disciplines and also acknowledges the uncertainty of changing conditions (Laurent et al. 2015).

Although other articles in this Special Feature focus on specific ecological and sociological components of adaptation in fireprone landscapes, this chapter highlights features of the engagement process between researchers as well as their interactions with multiple stakeholders (management agencies, landowners, and community leaders). In sum, this case study produced a set of lessons learned about interdisciplinary research team dynamics, team member interactions with agency personnel and community groups, and stakeholder's needs and expectations regarding the capability of our agent-based model.

By their very nature, CHANS studies have necessitated the involvement of agency personnel and key stakeholders (Liu et al. 2007). These two groups are not only important for helping researchers understand local conditions and priorities, but management agencies are also seeking advice and decisionsupport tools to assist in developing management strategies. This trifecta of research scientists, agency managers/technical experts, and community members, all with various levels of knowledge and interest in ecological and social landscapes, is a rare blend (Steel et al. 2004). For several decades, agency personnel and local stakeholders have attempted, with varying degrees of success, to come together for planning purposes to make land management decisions (e.g., Fischer and Charnley 2012, Shindler et al. 2014). But disciplinary scientists are relatively new participants in this

${ }^{1}$ Department of Forest Ecosystems \& Society, Oregon State University, ${ }^{2}$ USDA Forest Service Pacific Northwest Research Station, Corvallis, Oregon, ${ }^{3}$ Department of Biological \& Ecological Engineering, Oregon State University, ${ }^{4}$ USDA Forest Service, Pacific Northwest Research Station, Corvallis, Oregon 
collaborative mix, and some in this group may not have the time or inclination to be part of this arrangement. Not only is CHANS research putting these scientists into the fray of public policy but, in some settings where modeling alternative futures is underway, they now are expected to have a leadership role.

As three lead scientists from the primary interests of this study (social science, ecology, and systems analysis), we have written this piece based on multiple perspectives. These result from numerous qualitative methods including (1) oral and written assessments by science team members throughout the 4-year project, (2) compilation of feedback from stakeholder workshop participants, (3) discussions with graduate students who participated in climate change scenario development, (4) interactions with other science teams and management personnel that have experience in recent interdisciplinary research, (5) as well as our own personal assessments of project development. Our intent is to describe insights from these interdisciplinary efforts, discuss our interactions with multiple stakeholders, highlight what we have learned for the next iterations of the FPF project, and, where appropriate, relate what we have learned to the CHANS multiparty participatory process.

\section{RESEARCH CONTEXT}

The CHANS approach seeks to understand the complex nature of the interactions among human and natural systems as a means to solve pressing environmental and social problems (Liu et al. 2007, Stokels et al. 2013). Although a relatively recent strategy, CHANS stems from the larger transdisciplinary arena integrating ecological and social knowledge. Most notable is the field of adaptive management, the study of which first brought researchers and practitioners together in the 1990s, often to examine changing social-ecological systems in and around federal forest lands (Stankey et. al. 2005) and, more recently, changes to climate and fire regimes (Armatas et al. 2016). Now as a number of CHANS and other climate change studies have been completed, a good share of these have incorporated a similar component, one that identifies the lessons learned from the interdisciplinary approach taken (e.g., Halofsky et al. 2011, Millington et al. 2011, Hall and O'Rourke 2014). Often this has also included learning that accrued from team interactions with resource managers and other stakeholders.

However, the vast majority of management personnel and research scientists have had little experience in true multistakeholder collaborative processes. Too many still use the language of "we just need to educate the public" to gain acceptance for programs. Improving the ability of agencies and stakeholders to adapt to changing conditions requires more than information transfer and public outreach. As Ruppert-Winkel et al. (2015) noted, multidisciplinary science that genuinely incorporates multiple parties can help address real-world sustainability problems. Yet, there is increasing complexity in communicating and coordinating such efforts. For example, a cautionary observation about such activities comes from research on bridging techniques by Hahn et al. (2006). They noted that an important barrier to combining knowledge systems is that people with one frame of reference may not perceive or value the knowledge generated by other people's systems. These barriers can contribute to lack of understanding, inability to properly communicate concepts, unwillingness to adopt little known approaches, or distrust among individuals (Blades et al. 2016). Still, there is growing recognition that the complex and multiscale nature of environmental problems demands participatory and transparent decision making that is flexible to changing conditions (Hubacek and Reed 2009).

In acknowledgement of this, federal programs have recently been initiated to address adaptive capacity by creating networks that are intended to foster learning, multiparty problem solving, coordination of management actions, and the development of trust among parties (Shindler et al. 2014, Spies et al. 2014). For example, programs such as the National Cohesive Wildland Fire Management Strategy, the Healthy Forests Restoration Act, and the previously mentioned CFLRPs all encourage collaborative planning processes among government agencies at all levels along with property owners and community residents. Additionally, the Joint Fire Science Program (a research collaborative of the six federal agencies who manage lands affected by wildfire) has created a regional network of knowledge exchange consortia to bring together related fire science and provide methods for disseminating it to multiple audiences (JFSP 2016). Researchers from public agencies and universities (e.g., McCaffrey 2006, Olsen and Shindler 2010) have also joined in many of these efforts to help provide technical assistance as well as to monitor and evaluate this collective action and associated outcomes.

Two previous studies that highlighted these scientist-practitioner collaborations in landscape-level processes provide useful comparisons for our own case study. Gustafson et al. (2006) advocated for bringing together researchers, management planners, and community stakeholders in a collaborative, iterative approach. The collaborative aspect provides settings and conditions under which parties can explore shared issues of current and future concern. The iterative nature of the process allows for a progressive refinement of research methods and modeling capabilities. This approach is one that is intended to foster a "community of practice" in which all parties build understanding in a familiar social, physical, and temporal setting (Allee 1997). The use of a computer model is central to the process because it serves as a common framework to conceptualize and formalize management problems.

Subsequently, Sturtevant et al. (2007) followed with a similar approach to balance the science and local objectives on a forested landscape in central Labrador. They used methods that included a modeling strategy along with a multistakeholder collaborative process to help build the model. Their initial intent of the iterative collaborations was to identify essential management questions as well as available data resources. This led to specific determinations about the viability of existing tools or whether new tools could be rapidly created and applied within the model. Although the over-riding motivation for their research was finding ways to achieve a balance between more generalized "top-down" scientific solutions with more case-specific customized "bottom-up" modeling tools, they spent considerable effort on collaborative processes necessary for rapidly assembling and applying the models to new locations. Thus, a substantial component of this research centered on balancing efficient transfer of science with adaptation to local needs.

Both studies suggest that collaboration and iteration produce important outcomes. For example, Gustafson et al. (2006) 
indicated that under this format (1) model results are of greater quality and relevance to the decision maker, (2) managers learn to use a new technology, (3) researchers learn about management problems and associated constraints, and (4) resource experts come to better appreciate the interactions and realities of multiple-use planning. Sturtevant et al. (2007) concluded by noting that "if such dependencies are ignored, the process can easily degrade into an uncoordinated set of modeling exercises and the opportunity for true synthesis will be lost."

Thus, our team prioritized the importance of working at the landscape scale (central Oregon) with multiple federal and local agencies as well as several regional NGOs and key stakeholder publics (small and large landowners). Because our project was highly sensitive to the incorporation of social science data, we paid close attention to opportunities where information related to the human side of our CHANS research could be utilized or featured in assessments.

\section{RESEARCH APPROACH}

Instead of experimenting with new or unfamiliar management practices and learning from the results of these actions, we followed a protocol similar to Hubacek and Reed (2009). We used established simulation models of vegetation, fire, and agent behavior (Bolte et al. 2007) to incorporate data from existing studies and Forest Service records regarding current forest health, fire frequency and intensity, and other ecological conditions, e.g., plant species, biodiversity, soil erosion. We also were able to access population growth and movement trends from other government agencies; we were particularly interested in potential changes to the Wildland-Urban Interface. Although the component models were relatively well established, considerable effort was required to integrate them into an agent-based model framework and incorporate new information about landowner behavior. Social scientists on the team contributed new research on landowner wildfire risk, mitigation, adaptive capacity, and social network analysis. Following on the participatory research of Johnson et al. (2012), our intent was to discuss primary concerns and management capabilities with agency personnel and community stakeholders as well as explore different scenarios. Through our modeling capabilities we intended to then demonstrate anticipated consequences of various management interventions. We wanted to combine the knowledge and priorities of management agencies, community stakeholders, and social and natural scientists to anticipate, monitor, and adapt to change over time.

Similar to Gustafson et al. (2006), our initial approach was to meet with agency personnel from targeted study sites to describe the nature of our project and its multiple components, then to enlist their support, open the door for broader participation, and build relationships for what would be a multiyear effort. At the heart of this broader participation were the Deschutes and the Fremont-Winema National Forests and two associated, newly established Collaborative Forest Landscape Restoration Projects. This federally based CFLR program provides funding to local collaborative groups to plan science-based, economically viable fuel reduction and ecological restoration activities on national forest lands. The CFLRP's provided a ready-made diverse population of stakeholders who had interest in fire adaptation issues. Additional participants included the Bureau of Land Management, representatives from state and local agencies, regional NGOs and environmental groups, the timber industry, and key community leaders. We took the approach that our basic audience included anyone interested in these restoration needs and activities; thus, most of our presentations involved an "open door" policy.

Other specific forms of interaction over the course of the project included a scenario development class for graduate students who also met with stakeholders to present/discuss alternative futures, a series of on-site community workshops to demonstrate project progress, and a workshop involving scientists with CHANSrelated interdisciplinary experience. Also of benefit to our project were a number of previous studies that team members had independently conducted in the region, which included long-term relationships with resource agencies and members of NGOs.

\section{LEARNING FROM THE FPF CHANS PROJECT}

This case study produced a series of lessons learned about CHANS research team dynamics as well as their multiparty interactions. Unlike other data used in previous chapters of this journal, the following discussion comes largely from anecdotal evidence distilled throughout the life of the project. As mentioned, this derived from team member (verbal and written) input, feedback from agency and community participants, graduate students engaged in scenario workshops, and personal observations of the lead researchers.

Certainly, many of these observations are not unique to our project alone (e.g., Littell et al. 2011, Hall and O'Rourke 2014). Yet, they may serve to reinforce common findings or add new perspectives that have gone unidentified thus far, especially as they relate to interdisciplinary work and CHANS in fire-prone landscapes. Thus, the following discussion is meant to provide learning insights for other interdisciplinary teams as well as for our own evolving team to help inform future iterations of our CHANS research. Thus, for our purposes (as it would be for any research effort) it is important to record key elements that influenced our process of working together and interacting with multiple parties. The following discussion highlights eight such lessons from our project.

\section{Attention to forming a team of dedicated, highly skilled, and} respectful individuals from the outset is a universal starting point. Each scientist brings a particular disciplinary strength to a project, and their presence or absence (or balance) will influence how a project plays out. Virtually every CHANS or interdisciplinary team has, often in postproject evaluation, noted the importance of getting the "right individuals" together on the project. Competency is certainly a requirement; however, personalities, relationships, and familiarity with one another are all essential to an integrated group effort. One straight-forward approach to assembling a team is to start with people you respect (Shindler and O'Toole 2004). In short, if we do not attend to developing positive working relationships, we can probably forget about the science.

From a practical standpoint, assembling a scientific team under the tight deadline of proposals is difficult and involves some uncertainty in getting the right disciplinary and personality mix. 
In our case, we were interested in ensuring capacity in the social sciences; thus, we included researchers from anthropology, economics, history, and sociology, although many had not worked previously on large interdisciplinary teams. This diversity of disciplinary backgrounds enhanced our ability to both investigate multiple actor groups and contribute to models that represented their actions. But as with other interdisciplinary teams (e.g., Ruppert-Winkel et al. 2015), it is only after the research is funded and work begins that it becomes clear how well different team members actually fit in the evolving project.

An interesting observation about team dynamics came out at a postproject review session. As scientists, we tend to overlook many of the numerous ways individual personalities can influence the weight of representation of the given disciplines and approaches. In retrospect, one of our team members reflected on how traits such as salesmanship, likability, energy level, and even sense of humor can factor into adoption of an idea or approach. As a precautionary measure, this individual suggested teams should work to draw out potentially competing visions from quiet team members, and also play devil's advocate with ideas that seem to come to acceptance rather quickly. These ground rules could also serve as a way to keep members engaged. Adopting such behaviors within the group can influence project focus and outcomes, particularly when alternatives include individuals either staying at the table or walking away because they have been marginalized.

Research teams also benefit from bona fide "team activities" including taking field visits together, frequent meetings, and early efforts to outline and develop written products, even if they are primarily conceptual. Field visits, in particular, offer a variety of benefits. Being "out on the ground" can help the team focus together, to see each member's role, to understand what individuals bring to the project, and where alliances might be formed. These activities can clarify the context in which the project is embedded and empower participants to become more involved. While a number of team members participated in agency-organized field trips, our team did not carry this form of interaction over in any substantive way with our stakeholder groups. Hubacek and Reed (2009) recognized the value in using the landscape as a classroom to enhance learning among parties through shared experience and give-and-take discussion. In an era of remote sensing and computer modeling, going out in the field may seem antiquated but it is essential for building deeper understanding of the system and relationships with stakeholders that can foster joint learning.

Although having team players is essential, or at least desirable, we should also acknowledge the importance of strong leadership. Numerous researchers (e.g., Shindler and O'Toole 2004, Hahn et al. 2006) recognized the role of a central leader as a key factor in successful interdisciplinary projects for a diversity of reasons: (1) few rules exist for conducting such research as there might be for single-discipline projects; thus, a strong guiding individual is essential, (2) some scientists initially may have little team experience and will need help to create a more open discovery process, (3) research teams need leaders who function well in larger multistakeholder settings, and (4) leaders need to be able to articulate the common goals for the project and be a spokesperson for the group.
Conceptual and simulation models influence the way integration research is organized and interpreted.

As many interdisciplinary teams have noted, modeling can be difficult and often requires much more time and effort than initially planned (e.g., Hubacek and Reed 2009, Hartter et al. 2015). We all have had to face the fact that interdisciplinary research involves a different skill set than disciplinary research. It is like learning to live in another culture, one in which team members need to appreciate often very different worldviews. Thus, everyone has to learn another language, or collectively devise one for the group. Everyone also has to develop the capacity to explain themselves in ways that are widely intelligible. This is part of the value of building models together, where teams can develop a shared language and understanding.

But going deeper, this also may mean understanding if there are disciplinary issues with the modeling framework. For example, the science gaps in our landscape were larger for the social sciences (e.g., factors influencing perceived risk and land management, behavior of different landowners) than for the biophysical sciences where models of succession and fire behavior are relatively advanced. The exception for this Special Feature were the economists on the team, who fall under the larger social science umbrella, but had more frequent experience with models and tended to be model oriented. Although the group of humandimensions related social scientists certainly perform quantitative studies, one issue is that they often deal with a complex social system, including demographic and cultural shifts, that make development of quantitative, e.g., simplified, models and their predictions more difficult (Paveglio et al. 2014).

Despite the allure of computational models showing how people adapt to their environments, designing such models often requires distillation of social theory into simple decision rules (Fischer et al. 2013). Although the models may provide detailed output, e.g., maps and land use projections, they may not always allow room for rich and extended examination among parties. The translation between social science data and model programming is a pivotal place in the integration process. As observed elsewhere (e.g., Hahn et al. 2006), our group of social scientists were initially wary of the use of their data for modeling purposes as well as how, and by who, it would be interpreted. Just as other research teams have noted in similar studies (e.g., Ruppert-Winkel et al. 2015), the social scientists wanted to be sure that Envision's built-in decisionmaking routines were well anchored in recognizable social science theory. Fortunately, three team economists played a role in social scientists and modelers coming together to adequately bridge knowledge gaps. One outcome was the strong reiteration that the model intent is to explore potential futures rather than predicting particular outcomes. One lesson here is that early internal team discussions need to address concerns such as model capabilities and limitations, preferred spatial scale, data format requirements, and even how modeling results could best be represented for stakeholders.

Our strategy to address these concerns was twofold. First we held frequent "all-team" meetings early in the project to develop a shared conceptual model of our study system, explicitly discussing linkages within and across the biophysical and social domains. We also adopted an approach to whole system modeling that initially focused on relatively simple statistical models. These 
Table 1. Important points of interest to agency and stakeholder groups in the study area.

\begin{tabular}{ll}
\hline \hline $\begin{array}{l}\text { Federal/State Management Agencies } \\
\begin{array}{l}\text { Key natural resource values of concern to community and } \\
\text { community leaders }\end{array}\end{array}$ & $\begin{array}{l}\text { Community Stakeholders } \\
\text { risk }\end{array}$ \\
$\begin{array}{l}\text { Problem of managers and citizens thinking of landscape on } \\
\text { different scales }\end{array}$ & $\begin{array}{l}\text { Landscape scale planning; building frameworks for more collaborative work } \\
\text { Issues involving cross-boundary management }\end{array}$ \\
$\begin{array}{l}\text { Interest in modeling techniques that integrate social values and } \\
\text { how outcomes influence the landscape }\end{array}$ & $\begin{array}{l}\text { Tools for seeing how ecological and social scenarios will play out in the near and } \\
\text { long term }\end{array}$ \\
$\begin{array}{l}\text { Ability to use modeling in National Environmental Policy Act } \\
\text { and Forest Plan Revisions }\end{array}$ & $\begin{array}{l}\text { Types of educational and outreach activities and their usefulness for informing } \\
\text { citizens }\end{array}$ \\
$\begin{array}{l}\text { Building citizen trust for communication on fire risk and planned } \\
\text { management actions. }\end{array}$ & \\
\hline
\end{tabular}

could then be refined through the project lifetime as we learned more about the biophysical landscape and the needs/interests of our management partners. This "start simple, add complexity as needed" philosophy provided a ready entry point for each scientist to contribute to the modeling effort and allowed the project team to get an early sense of key processes and interactions in the model.

These sessions also provided periodic opportunities to enhance communication among the scientists. "Why are we seeing that result?" was a common question that often led to rich interdisciplinary conversations. Getting early results based on imperfect models in forms that promoted these conversations was essential to prioritizing model enhancements and fixing "bugs." For interpreting results, we found that framing outputs in terms of storylines, e.g., expansion of the wildland-urban interface (WUI) or increase in drought conditions, that emphasized relevant cross-disciplinary themes in the project was an effective way to communicate results both internally and to our outside stakeholders.

Finally, another observation about using simulation models was made at the conclusion of our project. We recognized that without the model we would have had a lot of interesting research projects (and conversations), yet they would not be integrally connected nor effectively inform other aspects of the CHANS research. Still, although models are a useful framework for integration, and are often at the center of such efforts, we believe they should not be considered the all-inclusive end product. The models cannot speak for themselves. The key function of evaluating these complex systems remains with scientists and management personnel, and the model is just a tool to gain understanding. It may be more useful to view the model as both a project and discipline integrator.

Where projects involve interactions with stakeholders, the engagement should come early, well before the model is completed or results produced.

Because of various time and travel constraints, our workshops with management personnel and citizens were abbreviated oneday versions of a process that normally would take several days.
In such cases, preselection of and commitment by stakeholders is essential. Their participation over time is an important component to developing a fuller understanding of the research, trustworthy relations with scientists, a focus and useful feedback on specific climate change factors, and a rich discussion throughout the term of the project (Shindler et al. 2014). This level of participation also leads to a greater potential for managers and stakeholders to work together once the research team leaves the premises (Hubacek and Reed 2009).

Initial meetings with stakeholders are a time for description of the overall project and to focus project objectives and expectations in clear and meaningful terms. Both inputs and anticipated outputs of the model need to be communicated to participants in a transparent manner; otherwise, the model may simply be viewed as a "black box" (Hubacek and Reed 2009, Millington et al. 2011). It was clear our participants wanted to go well beyond this black box notion because they brought their own set of ideas and questions to our meetings. Tables 1 and 2 characterize the nature of their interests. Of course, these served to make our workshops more interactive.

Over time and discussion, we learned that agency personnel had a list of significant activities about which they were looking for help, including (1) a method to align landscape scenarios, tradeoffs, and outcomes for public discussion, (2) depicting where specific actions are necessary, such as prescribed fire and smoke management, (3) showing management strategies/options for wildlife habitat, recreation use, water systems, etc., (4) demonstrations of an "all lands" approach to management, (5) ways to demonstrate how management plans could be based on values and funding, and (6) help with the National Environmental Policy Act (NEPA) and forest planning processes, essentially to increase transparency of the agency.

Obviously, not all of these management needs fit neatly into our research agenda or modeling capabilities. Nor were all agency and community interests in alignment. But we learned from this exchange, and it opened the door to another important aspect of our interactions. It provided a useful method for setting expectations about what is possible and what the model can 
Table 2. Examples of interests of agencies and stakeholders in application of the ENVISION model.

\begin{tabular}{|c|c|}
\hline Federal/State Management Agencies & Community Stakeholders \\
\hline $\begin{array}{l}\text { Align scenarios/outcomes for public discussion, use model to } \\
\text { increase transparency of agency }\end{array}$ & Coordinate decisions on local level with stakeholder engagement \\
\hline Show trade-offs between management options & $\begin{array}{l}\text { Compare areas for greatest benefit of treatment, including best/worst case } \\
\text { scenarios }\end{array}$ \\
\hline & Demonstrate to lay people that computer model is valid and trustworthy \\
\hline Show how plans are developed based on values, funding, etc. & Examine level of increasing risk from climate change \\
\hline $\begin{array}{l}\text { Ability to show how climate change will influence fire regimes, } \\
\text { habitat, population, etc. }\end{array}$ & \\
\hline $\begin{array}{l}\text { Examine levels of smoke and smoke management people will } \\
\text { tolerate }\end{array}$ & $\begin{array}{l}\text { Want a map of values to understand how fire hazard and city planning might } \\
\text { intersect; influences on water quality }\end{array}$ \\
\hline Understand how social networks connect newcomers to region & $\begin{array}{l}\text { Seeing where the wildland-urban interface/urban growth boundary might grow } \\
\text { and what citizens need to know }\end{array}$ \\
\hline $\begin{array}{l}\text { Model needs to be easy and accessible; do not want to be } \\
\text { dependent on Oregon State University }\end{array}$ & User friendliness, explanation of model assumptions \\
\hline
\end{tabular}

currently produce. We recognized that a transparent approach is just as important for scientists as it is for agencies when developing management plans. Through the process of describing the project, focusing the objectives in clear language, and setting realistic expectations, our research team learned a great deal about what our constituents were looking for to support their on-the-ground work. For example, we added a smoke production submodel to Envision after discussions with stakeholders. Although their management needs often exceeded our current modeling capability, these give-and-take discussions provided a substantial amount of information to serve as targets for future project iterations.

Along with recognizing disciplinary roles, there is great value in identifying a subset of team members who can integrate data sources and modeling capabilities.

The critical role of bringing the science team together and sustaining progress typically falls to disciplinary leaders who will need to provide leadership throughout the project. Certainly this includes scheduling regular sessions with the full team and an eye for fluid, meaningful communication. This will often mean making sure the different disciplines are contributing in ways that make sense to the cross-section of researchers.

Over time, different individuals became recognized by skill type and contributions made to the project. First were the "idea people" who tended to conceptualize and develop a vision of the way forward. Second were the "doers" who saw the vision and were able to execute it by combining data, analysis, and models. These individuals may receive assistance from the "specialists" who are particularly apt in understanding or executing their specific discipline, e.g., wildlife habitat modeling. Finally, certain people were recognized as "connectors," those who were able to see the various ideas, specific approaches, and data of different disciplines and translate this into a cohesive whole. As our project evolved, these individuals used their crossover skills to help interpret intentions and outcomes among research protocols. Thus, one lesson here is that recognition of skills also helps to identify who can best fill important roles and how alignment can be created.

Finally, we all learned that we needed to be adaptive to respond to unforeseen problems, needs, and opportunities. Any team that has submitted a research proposal knows that being specific and targeting proposal requirements are essential to being funded. However, seeing the funded project as the final blueprint for research is a limited perspective. A functional research plan for a CHANS project requires many months of team engagement to properly develop a common understanding of the diversity of perspectives and how to best apply them. Goals may emerge during the research process in much greater clarity and also trust among team members increases (Ruppert-Winkel et al. 2015).

Team member peer review is of particular value.

The euphuism "everyone talks but hardly anyone is listening" is one that could describe many research team meetings, but still is a situation that needs to be addressed. From different disciplines and different audiences come different values, needs, and forms of understanding. As a team we forced ourselves to listen to and learn about the research of others, initially so we could all try to make our own research relevant and feed the model accordingly. We learned that at no time has the value of internal peer review ever been as evident as in this interdisciplinary project. As the project matured, we learned that presenting our findings and observations to one another also helped us to prepare for our much more public interactions. For example, we did a number of trial-run PowerPoint presentations among the team with each discipline critiquing the work of another for clarity, understandability, and fit into the overall project. Prior to a key stakeholder workshop, team members also presented the project concept and their research to a university graduate-level natural resource decision-making class, essentially another trial run before going public. Collectively, these activities were quite useful in helping team members develop a shared understanding and a common method to communicate with one another. They also were confidence boosters for less experienced scientists on the team. 
These activities also helped team members recognize the need to develop writing skills that did justice to the interdisciplinary nature of our work. Essentially, writing about topics that cross disciplinary lines is no easy task (Spies et al. 2014). This became particularly evident as coauthors teamed up on research publications at the conclusion of this project when some of the most interesting results from the models were produced. The development of scientific papers after the official end of the project (in terms of the funding agency) was one of the most critical stages for integration, and produced some of the best learning experiences for individual researchers. Although scientific manuscripts are at the pinnacle of integration, the foundation for working together on them was laid in the years spent in meetings to design the study, report initial results, understand each other's disciplines and language, and build mutual trust.

\section{Overcome the "what now?" factor.}

This "what now?" idea involves fulfilling agency and stakeholder expectations. All along we had no problem finding interested practitioners who watched, listened, and commented as we displayed our model scenarios and the implications of our findings. Agency personnel were encouraged about the potential benefits of agent-based modeling and obtaining new insights to inform their management options. However, herein lies a common theme among management personnel that all CHANS research teams are likely to face. For practitioners, a logical next step is getting to how they could use these tools themselves. Most wanted scientists to engage in a shared learning process that included participatory research. In other words, the degree to which interactive modeling could be used by managers and stakeholders together to construct scenarios and model assumptions.

From the aforementioned list of management needs, this participatory feature is one that agencies seem to be looking for, particularly ways to get the model to help them with public process. For example, they hoped the model could provide onthe-spot information to assist with stakeholder understanding, public outreach, or even NEPA planning processes. In the point of view of one agency workshop participant, "We are not thinking about this in terms of decision support, instead we want discussion support." Other concerns were directed at being able to see upcoming risks and potential answers. For example, at the end of one scenario meeting a stakeholder said he was disappointed that we did not deliver a "golden egg" of knowledge. From a research standpoint, our intention in being there was to understand their views on alternative futures for the local landscape. However, as with other research teams (e.g., Hubacek and Reed 2009), we had not fully acknowledged the heterogeneous composition of our participants in terms of their views, interests, and formal education level. About midpoint in the project we recognized that better forms of hands-on technical transfer and decision support were important deliverables.

Our team pondered these stakeholder expectations but as other researchers have found, broad-scale interactive modeling is time consuming and unpredictable (Hubacek and Reed 2009, Schmitt Olabisi et al. 2010), often because of the difficulty in developing new technology that is accessible and fits with various players' values and interests. As many large companies (e.g., Boeing) and government institutions (e.g., federal health care) have found, meeting deadlines for functional hardware and software is easier said than done. Contingencies need to be made for not having technology fully ready in time to meet the expectations of multiple participants (Johnson et al. 2012).

In the end our research team met numerous project objectives and, as this Special Feature reflects, learned much along the way. Still, when the project deadline came, considerable work remained in order to hand over modeling tools to agency technical and management personnel for their own specific use, as well as time allotted to "train them up" on the sophisticated software. As with other research efforts (e.g., Measham 2009, Johnson et al. 2012), we learned that the length and form of engagement is essential to participants understanding modeling systems as well as building trust in the process. Allowing time for informal engagement is particularly important, where participants have sufficient time to work alongside one another and more fully assess various data applications and scenario outcomes. Fortunately, the capacity we have built in terms of models, data bases, and individuals has helped us to leverage additional funds to continue our efforts. Thus, we now have an FPF 2.0 in which the full capacity of what we have produced is ready for further engagement with agency and citizen stakeholders. Not all research projects that are typically funded for three to four years have such opportunities. Unless adequate time, funds, and personnel are allocated to this follow up component, it is unlikely the specific attributes of the model will be continuously available for on-the-ground planning purposes.

CHANS research teams do not necessarily need to create new presentation forums for collaborative action and education

Too often the research and management culture has been one where "we need to host a meeting (or workshop) to invite others in so we can share our information with them." These formats have met with varying degrees of success, but one particular feature is evident. When the public meets only at agency workshops and only with research or management personnel, these efforts are difficult to sustain (Shindler et al. 2014). Alternatively, it is useful to look for additional venues where our research products may be useful. These could be large-scale projects or programs already underway where multiple stakeholders have come together and have a working relationship. In these cases, researchers may be able to piggyback on these efforts and add value to them. Joining in with these collaborative groups can save the research team considerable time in developing the societal engagement part of the project. For example, in the FPF project our two primary study sites already had Collaborative Forest Landscape Restoration Programs underway and local collaborative groups were forming. With their participatory approach, these groups provided a window into natural resource concerns already identified by local stakeholders. It also became apparent that these fledgling efforts were looking for help from the research community.

This more interactive form of ongoing communication and collaboration could help solve an additional problem observed in other studies. In similar projects, participants in one day workshops generally responded well to the information exchange process among scientists, managers, and stakeholders. However, these short vignettes about such massive topics (wildfire effects or climate change) were insufficient for fostering in-depth 
understanding or an enduring relationship that would result in management actions (e.g., Wright 2010, Blades et al. 2016). More optimistically, both Sturtevant et al. (2007) and Millington et al. (2011) indicate that an approach that establishes a long-term connection and commitment among partners is a likely requirement for substantive information transfer and sufficient collaborative action. We advocate that such efforts will need a formal multiagency program at the federal scale, complete with resources to do the job, including committed leadership, additional training for personnel and stakeholders, and adequate funding. These alliances can also help address the "what now?" dilemma.

\section{Recognize the importance of strategic communication versus good communication}

Everyone acknowledges the value of good communication skills when working in groups and across disciplinary lines. However, the notion that we will educate the public at a workshop or meeting is a classic mistake. One problem, as Gustafson et al. (2006) noted, is the tendency of scientists in these settings to dwell exclusively on the model details, i.e., the technology. For example, without proper setup the often highly realistic maps that our landscape models produce can be deceptive to stakeholders who mistake these outputs as predictive rather than speculative (Duncan 2006, Fischer et al. 2013). In a CHANS study other very real problems may arise if the climate change topic is introduced as a central opening feature. This subject is highly complex, includes high levels of uncertainty, and potential solutions may seem extremely long-term in nature. Simply, it may be a nonstarter for many nonscientific audiences (Ruppert-Winkel 2015).

Fortunately, our team took a more strategic approach. From the numerous disciplinary studies our team members had previously conducted in the region, we knew that many related problems were high on peoples' agendas. As noted, central Oregon is highly prone to wildfires. This is a relatively easy topic for stakeholders to gather around, even those with diverse perspectives; simply, no one wants their place to burn up. Additionally, invasive species, insect infestation, drought, and an expanding WUI are all problems that most people in local communities were ready to talk about. We were able to capture their attention and maintain a civil discourse because early on we focused around each of these issues, and eventually conversations came around to climate change. Additionally, we recognized this is certainly one place where our team peer review sessions paid off. We were able to help one another put the language of our sciences into useful, more audience-targeted terms.

We also recognized the value of two other strategic features that have been used successfully by interdisciplinary science teams: boundary objects and boundary experiences (e.g., Feldman and Khademian 2007, Blades et al. 2016). Both of these techniques represent methods whereby people can come together and transform their knowledge and, more importantly, where discussions are more inclusive. For use in a research context, boundary objects can be pictures, graphs, maps, planning documents, or some related visual tool. We employed all of these in our workshops as informational/teaching tools centered on areas such as wildfire risk, fire mitigation, juniper encroachment, invasive species, public-private boundaries, etc. In this way we were able to bring the outputs of our modeling technology into the discussions. Subsequently, this also generated conversations among stakeholders who were familiar with these places and issues and now had a common format for expressing themselves.

The boundary experience idea incorporates joint activities or shared places where people can acquire and provide information. Settings such as field trips, community forums, homeowner association meetings, or work parties exemplify the intended outcome of creating communities of interest for discussing problems, concerns, issues, and, in our case, management alternatives. Particularly when these are familiar places, it is easy to generate interest/discussion about changing conditions and adaptive solutions, essentially using these landscapes as classrooms. In retrospect, our project team did not take full advantage of the boundary experience approach. However, the two local CFLRP groups have used this methodology to advance their proposed projects. Organized bus trips to wildfire sites and stream restoration areas have generated considerable support for management action as well as improving community-agency relations (Shindler et al. 2014).

The over-riding message in this lesson seems clear; however, it may have best been said in George Bernard Shaw's iconic statement: "The single biggest problem with communication is the illusion that it has taken place." In the case of interdisciplinary CHANS research, good communication may not be enough. More strategic methods of engaging our stakeholders seem necessary. As Groffman et al. (2010) noted, effective communication of science to the public requires understanding that most learning occurs outside of meeting rooms and is influenced by learners' interests, prior knowledge, social networks, and personal values.

\section{CONCLUSION}

No doubt, each disciplinary group of scientists benefitted from our project and learned things of value along the way; each had their own goals and motivations in addition to the overall project goals. However, in this paper we focus on the interdisciplinary nature of the CHANS approach and what we learned about working as a team, as well as what we learned about our multistakeholder audience. Ultimately, our ability to do the necessary research and also make it meaningful beyond our central team is an essential aspect of the CHANS program.

On balance, we recognize a central element of the CHANS concept is that we work in a world of uncertainty. We have come to know this and have taken a scenario approach to examine societal changes and the potential outcomes of various management actions. Underlying this world of uncertainty is how we talk about these ideas as well as how we describe what we do know about these models and what they represent. This suggests a need for more open communication and transparency (Fischer et al. 2013). One point here is that it may be time for researchers to get comfortable with using terms such as "I'm not sure" and "I don't know." Often our education and expertise seem to get in the way of our being able to do this, or even acknowledging this is an option. However, this openness can be quite meaningful to our stakeholders and can even help bridge the credibility and trust gap that often exists between citizen groups, resource agencies, and researchers (Shindler et al. 2014). This is also a prelude to dealing with risk and uncertainty in more realistic ways, a primary element of CHANS research that focuses on long-term landscape or climate change where periodic surprises are inevitable. 
Thus, public discussions need to go further than "here's our model, here's our science, here are a few likely outcomes." Presentations must be thoughtfully crafted to be relevant to managers and their community of stakeholders. Learning goes in both directions; scientists provide high quality information and management personnel describe important landscape level considerations as well as realistic management responses to changing conditions. For example, a useful approach with management audiences could be to frame the large spatial and temporal scale issues of landscape and climate change discussion around ecosystem restoration activities (Littell et al. 2011). These are concepts that agency personnel are familiar with and have a head start on implementing. Certainly an adaptive management approach and mentality will be necessary in our changing world where predicted effects may be uncertain or even conflicting.

The same adaptive approach seems useful for the research team. We recognize that interdisciplinary scientists have a lot to learn about, and from, one another to be effective as a team. CHANS research requires that we commit to being interactive. Two useful methods presented here include internal peer review and boundary experiences that enhance our ability to plan and work together. In addition, one of the frequently overlooked activities in such projects is the benefit that can be derived from postproject evaluation sessions. Rather than just walking away when the project funds and time-frame run out, committed team members can add greatly to learning processes with one or more debriefing meetings to share their experiences, both positive and negative. We all have many other things to rush off to, but this activity can reveal much for the next time around.

Finally, we recognize that many local (bottom-up) efforts to address landscape restoration or climate change are being encouraged, e.g., CFLRPs, Healthy Forests Restoration Act. But given the pace of the problem, it is unlikely these will be sufficient to change the course of management or public acceptance on a broad scale. We would be remiss if we did not also acknowledge the realities of transmitting CHANS research to an already overwhelmed management constituency. Quite simply, it is difficult to expect that our resource agency personnel can currently expand their management and planning responsibilities to include coupled human systems, multiownership landscapes (all lands management), or climate change in any significant way (Halofsky et al. 2011, Blades et el. 2016). For example, Gustafson and others (2006) cautioned about a number of difficulties in transferring complex decision-support models to agency personnel. Among these are the following:

- teaching managers and their support staff to run modeling software requires formal training and technical support;

- proper application requires that managers understand in some detail the assumptions behind the models and the limitation of results,

- managers must learn how to interpret a model's results to provide defensible support for their decisions;

- political, funding, or logistical limitations may constrain management options;

- a shared understanding of the role of uncertainty in the decision-making process is critical.
A common issue for management personnel, who otherwise believe that landscape science should be used in forest planning decisions, is that a number of constraints, i.e., time, funding, and political realities, severely limit their capacity to be involved in such efforts (Archie et al. 2012).

From this set of lessons learned as well as associated interdisciplinary research by our colleagues, it seems that a topdown, full-scale adoption of programs to address climate changerelated problems needs to be taken. Following the theme of the research discussed here, one solution could come in the form of our institutions designating personnel whose job is to bridge the efforts of scientists, resource managers, and stakeholders. Ultimately, if these efforts come to pass, this is likely to require some blurring of the traditional research and management relationship. As Littell et al. (2011) note, a science-management relationship is essential for both establishing the scientific basis for proposed adaptation options and having the management expertise in place to develop those options. As a research team the lessons presented here will help our FPF 2.0 efforts, both from the perspective of working together and with multiple stakeholders. We must engage with our audiences in new ways, frame our models in ways that resonate with these individuals, and use more strategic communication tools that can reach a wide range of target groups.

Responses to this article can be read online at: http://www.ecologyandsociety.org/issues/responses. $\mathrm{php} / 8776$

\section{LITERATURE CITED}

Allee, V. 1997. The knowledge evolution: expanding organizational intelligence. Butterworth-Heinemann, Boston, Massachusetts, USA.

Archie, K. M., L. Dilling, J. B. Milford, and F. C. Pampel. 2012. Climate change and western public lands: a survey of U.S. federal land managers on the status of adaptation efforts. Ecology and Society 17(4):20. http://dx.doi.org/10.5751/ES-05187-170420

Armatas, C. A., T. J. Venn, B. B. McBride, A. E. Watson, and S. J. Carver. 2016. Opportunities to utilize traditional phenological knowledge to support adaptive management of social-ecological systems vulnerable to changes in climate and fire regimes. Ecology and Society 21(1):16. http://dx.doi.org/10.5751/es-07905-210116

Blades, J. J., P. Z. Klos, K. B. Kemp, T. E. Hall, J. E. Force, P. Morgan, and W. T. Tinkham. 2016. Forest managers' respond to climate change science: evaluating the constructs of boundary objects and organizations. Forest Ecology and Management 360 (15):376-387. http://dx.doi.org/10.1016/j.foreco.2015.07.020

Bolte, J. P., D. W. Hulse, S. V. Gregory, and C. Smith. 2007. Modeling biocomplexity-actors, landscapes and alternative futures. Environmental Modelling \& Software. 22(5):570-579. http://dx.doi.org/10.1016/j.envsoft.2005.12.033

Duncan, S. L. 2006. Mapping whose reality? Geographic information systems (GIS) and "wild science." Public Understanding of Science 15(4):411-434. http://dx.doi. org/10.1177/0963662506061885 
Feldman, M. S., and A. M. Khademian. 2007. The role of the public manager in inclusion: creating communities of participation. Governance: An International Journal of Policy, Administration, and Institution 20(2):305-324. http://dx.doi. org/10.1111/j.1468-0491.2007.00358.x

Fischer, A. P., and S. Charnley. 2012. Risk and cooperation: managing hazardous fuel in mixed ownership landscapes. Environmental Management 49(6):1192-1207. http://dx.doi. org/10.1007/s00267-012-9848-Z

Fischer, A., A. Korejwa, J. Koch, T. Spies, C. Olsen, E. White, and D. Jacobs. 2013. Using the forest, people, fire agent-based social network model to investigate interactions in social-ecological systems. Practicing Anthropology 35(1):8-13. http://dx.doi. org/10.17730/praa.35.1.w7348256k283t131

Groffman, P. M., C. Stylinski, M. C. Nisbet, C. M. Duarte, R. Jordan, A. Burgin, M. A. Previtali, and J. Coloso. 2010. Restarting the conversation: challenges at the interface between ecology and society. Frontiers in Ecology 8(6):284-291. http://dx.doi. org/10.1890/090160

Gustafson, E. J., B. R. Sturtevant, and A. Fall. 2006. A collaborative, iterative approach to transferring modeling technology to land managers. Pages 43-64 in A. H. Perera, L. J. Buse, T. R. Crow, editors. Forest landscape ecology: transferring knowledge to practice. Springer, New York, New York, USA. http://dx.doi.org/10.1007/978-0-387-34280-1 3

Hahn, T., P. Olsson, C. Folke, and K. Johansson. 2006. Trustbuilding, knowledge generation and organizational innovations: the role of a bridging organization for adaptive comanagement of a wetland landscape around Kristianstad, Sweden. Human Ecology 34:573-592. http://dx.doi.org/10.1007/s10745-006-9035$\underline{\mathrm{Z}}$

Hall, T., and M. O'Rourke. 2014. Responding to challenges in transdisciplinary sustainability science. Pages 119-139 in K. Huutoniemi and P. Tapio, editors. Transdisciplinary sustainability studies: a heuristic approach. Routledge, New York, New York, USA.

Halofsky, J., D. Peterson, M. Furniss, L. Joyce, C. Millar, and R. Neilson. 2011. Workshop approach for developing climate change adaptation strategies and actions for natural resource management agencies in the United States. Journal of Forestry 109(4):219-225.

Hartter, J., F. R. Stevens, L. C. Hamilton, R. G. Congalton, M. J. Ducey, and P. T. Oester. 2015. Modelling associations between public understanding, engagement and forest conditions in the Inland Northwest, USA. PLoS ONE 10(2):e0117975. http://dx. doi.org/10.1371/journal.pone.0117975

Hubacek, K., and M. Reed. 2009. Lessons learned from a computer-assisted participatory planning and management process in the Peak District National Park, England. Pages 189-201 in C. Allan and G. H. Stankey, editors. Adaptive environmental management: a practitioners guide. Springer Science, Dordrecht, The Netherlands. http://dx.doi. org/10.1007/978-1-4020-9632-7 10

Johnson, K. A., G. Dana, N. R. Jordan, K. J. Draeger, A. Kapuscinski, L. K. Schmitt Olabisi, and P. B. Reich. 2012. Using participatory scenarios to stimulate social learning for collaborative sustainable development. Ecology and Society 17 (2):9. http://dx.doi.org/10.5751/es-04780-170209

Joint Fire Science Program (JFSP). 2016. Joint Fire Science Program science delivery and application strategy. JFSP, Boise, Idaho, USA. [online] URL: http://www.firescience.gov/ jsp consortia.cfm

Laurent, K. L., K. B. Friedman, G. Krantzberg, D. Scavia, and I. F. Creed. 2015. Scenario analysis: an integrative and effective method for bridging and achieving a thriving Great Lakes-St. Lawrence River Basin. Journal of Great Lakes Research 41 (1):12-19. http://dx.doi.org/10.1016/j.jglr.2014.10.002

Littell, J., D. Peterson, C. Millar, and K. O’Halloran. 2011. U.S. National Forests adapt to climate change through sciencemanagement partnerships. Climate Change 110(1):269-296.

Liu, J., T. Dietz, S. R. Carpenter, C. Folke, M. Alberti, C. L. Redman, S. H. Schneider, E. Ostrom, A. N. Pell, J. Lubchenco, W. W. Taylor, Z. Ouyang, P. Deadman, T. Kratz, and W. Provencher. 2007. Coupled human and natural systems. $A M B I O$ 36(8):639-649. http://dx.doi.org/10.1579/0044-7447(2007)36[639: CHANS]2.0.CO;2

McCaffrey, S. 2006. The public and wildfire management: social science findings for managers. General Technical Report NRS-1. U.S. Forest Service, Northern Research Station, Newtown Square, Pennsylvania, USA.

Measham, T. G. 2009. Social learning through evaluation: a case study of overcoming constraints for management of dryland salinity. Environmental Management 43:1096-1107. http://dx.doi. org/10.1007/s00267-008-9265-5

Millington, J. D. A., D. Demeritt, R. Romero-Calcerrada. 2011. Participatory evaluation of agent-based land-use models. Journal of Land Use Science 6(2-3):195-210. http://dx.doi. org/10.1080/1747423x.2011.558595

Olsen, C. S., and B. A. Shindler. 2010. Trust, acceptance, and citizen-agency interactions after large fires: influences on planning processes. International Journal of Wildland Fire 19 (1):137-147. http://dx.doi.org/10.1071/WF08168

Paveglio, T. B., C. Moseley, M. S. Carroll, D. R. Williams, E. J. Davis, and A. P. Fischer. 2014. Categorizing the social context of the wildland urban interface: adaptive capacity for wildfire and community “archetypes." Forest Science 61(2):298-310. http://dx. doi.org/10.5849/forsci.14-036

Ruppert-Winkel, C., R. Arlinhaus, S. Deppisch, K. Eisenack, D. Gottschlich, B. Hirschl, B. Matzdorf, T. Mölders, M. Padmanabhan, K. Selbmann, R. Ziegler, and T. Plieninger. 2015. Characteristics, emerging needs, and challenges of transdisciplinary sustainable science: experiences from the German SocialEcological Research Program. Ecology and Society 20(3):13. http://dx.doi.org/10.5751/ES-07739-200313

Schmitt Olabisi, L. K., A. R. Kapuscinski, K. A. Johnson, P. B. Reich, B. Stenquist, and K. J. Draeger. 2010. Using scenario visioning and participatory system dynamics modeling to investigate the future: lessons from Minnesota 2050. Sustainability 2:2686-2706. http://dx.doi.org/10.3390/su2082686 
Shindler, B., C. Olsen, S. McCaffrey, B. McFarlane, A. Christianson, T. McGee, A. Curtis, and E. Sharp. 2014. Trust: a planning guide for wildfire agencies and practitioners-an international collaboration drawing on research and management experience in Australia, Canada, and the United States. Joint Fire Science Research Publication. Oregon State University, Corvallis, Oregon, USA. [online] URL: http://hdl.handle.net/1957/45323

Shindler, B., and E. O'Toole. 2004. Integrated research in natural resources: an explanatory analysis of five case studies. U.S. Forest Service PNW Station Research Report. Oregon State University, Corvallis, Oregon, USA.

Spies, T. A, E. M. White, J. D. Kline, A. P. Fischer, A. Ager, J. Bailey, J. Bolte, J. Koch, E. Platt, C. S. Olsen, D. Jacobs, B. Shindler, M. M. Steen-Adams, and R. Hammer. 2014. Examining fire-prone landscapes as coupled human and natural systems. Ecology and Society 19(3):9. http://dx.doi.org/10.5751/es-06584-190309

Stankey, G. H., R. N. Clark, B. T. Bormann. 2005. Adaptive management of natural resources: theory, concepts, and management institutions. General Technical Report PNWGTR-654. U.S. Forest Service, Pacific Northwest Research Station, Portland, Oregon. http://dx.doi.org/10.2737/pnwgtr-654

Steel, B., P. List, D. Lach, and B. Shindler. 2004. The role of scientists in the environmental policy process: a case study from the American west. Environmental Science \& Policy 7:1-13. http:// dx.doi.org/10.1016/j.envsci.2003.10.004

Stokols, D., R. Perez Lejano, and J. Hipp. 2013. Enhancing the resilience of human-environment systems: a social-ecological perspective. Ecology and Society 18(1):7. http://dx.doi. org/10.5751/ES-05301-180107

Sturtevant, B. R., A. Fall, D. D. Kneeshaw, N. P. P. Simon, M. J. Papaik, K. Berninger, F. Doyon, D. G. Morgan, and C. Messier. 2007. A toolkit modeling approach for sustainable forest management planning: achieving balance between science and local needs. Ecology and Society 12(2):7. http://dx.doi. org/10.5751/ES-02102-120207

Wright, V. 2010. Influences to the success of fire science delivery: perspectives of potential firelfuels science users. Final Report to the Joint Fire Science Program Project \#04-4-2-01. JFSP, Boise, Idaho, USA. [online] URL: http://www.firescience.gov/ projects/04-4-2-01/project/04-4-2-01 vw jfsp final report.pdf 